Research Article

\title{
Research on Low-Frequency Swaying Mechanism of Metro Vehicles Based on Wheel-Rail Relationship
}

\author{
Yixuan Shi ${ }^{(D)}$, Huanyun Dai, Qunsheng Wang ${ }^{(D)}$, Lai Wei, and Huailong Shi \\ State Key Laboratory of Traction Power, Southwest Jiaotong University, Chengdu 610031, China \\ Correspondence should be addressed to Yixuan Shi; shiyixuan@my.swjtu.edu.cn and Qunsheng Wang; wangqunsheng@126.com
}

Received 8 May 2020; Revised 3 September 2020; Accepted 22 October 2020; Published 16 November 2020

Academic Editor: Peter Múčka

Copyright (c) 2020 Yixuan Shi et al. This is an open access article distributed under the Creative Commons Attribution License, which permits unrestricted use, distribution, and reproduction in any medium, provided the original work is properly cited.

For the worn state of the wheel, metro vehicles often suffer a serious carbody swaying issue, which causes the lateral stability of the vehicle to exceed the limit and affects the ride comfort. An experimental test was carried out on this investigation to study the carbody swaying of the metro vehicle. The field results show that the vehicle system vibrates at around $2.5 \mathrm{~Hz}$ in the lateral direction, which leads to the low-frequency swaying on the carbody. In order to explore the formation mechanism of the carbody low-frequency swaying and its relationship with the geometry matching of wheel-rail contact, measured rail and wheel profiles are employed to present a comparative analysis with respect to the initial contact geometry. A multibody dynamic railway vehicle system is established further. Time-domain simulations state that the $2.5 \mathrm{~Hz}$ vibration on the carbody belongs to the natural frequency of the vehicle, and the amplitude is larger for the measured wheels than that of the standard wheel profiles. By using the root-locus method, it can be determined that the $2.5 \mathrm{~Hz}$ vibration corresponds to the upper swaying mode of the carbody. With the increase in the wheel-rail equivalent conicity, the hunting frequency of bogie increases gradually, which converts frequency with the upper swaying frequency of carbody and leads to carbody low-frequency swaying.

\section{Introduction}

With urbanization processing, traffic jams and other problems caused by the rapid growth of the urban population have become more serious. Efficient, convenient, comfortable, and environment-friendly rail transportation system came into being and gradually became the main public transportation system in major cities [1]. However, problems such as vibration and noise caused by the vehicles have gradually emerged, which may affect the normal operation in serious cases. The vibration of the Paris metro line 7 and line 13 affected the performance of the Bastille Opera House when vehicles are passing. In the Czech Republic, ancient buildings near the rail transit line are cracked due to the vibration generated by vehicles $[2,3]$. When operating vehicles may cause interference to the surrounding residents in many cities, the vibration also causes adverse effects on passengers and the vehicle itself at the same time. During the operation of vehicles, when passing some sections of the railway lines, relatively severe lateral low-frequency swaying may occur, which affects the riding comfort and also affects the driving safety in serious cases, and the stability of the carbody is certain to exceed the limit at this time.

The low-frequency swaying of vehicles will increase the impact between wheel and rail, which will affect the wheelrail contact relationship, increase the wheel tread wear, and reduce the service life of wheels in long-term operation. It will have certain effects on other parts of the vehicle, especially the bogies and suspension systems; long-term lowfrequency swaying will cause mechanical damage to the structure, seriously affect its performance, also reduce the vehicle reliability, and bring great safety risks at the same time [4]. Many researchers have started their research on vibration characteristics and environmental response during metro vehicle operation long before. Problems of railwayinduced ground vibrations are presented along with experimental studies to assess the ground vibration and ground-borne noise levels by Kouroussis and his colleagues [5]. In in situ experiment, Nie considers that the vibration created by urban metro transit with great influence on 
adjacent buildings is mainly concentrated on the low band below $20 \mathrm{~Hz}$ [6]. Recently, some specific studies focused on the vehicle low-frequency vibration. Huang established a multibody dynamic model reflecting the coupling relationship between the carbody and bogie, analysed the key influencing parameters of carbody hunting, and used the linear analysis method to analyse the law of sensitive parameters on the lateral abnormal swaying of high-speed vehicles [7]. Jonsson pointed out that the hunting motion of the carbody at low speed is caused by the resonance of several modes inherent in the carbody, including low-frequency swaying [8]. Xia and his team presented a measurement that was based on vibration signal detection and active low-frequency vibration absorption to detect and control the low-frequency swaying [9]. According to the method Euclidean Closeness of fuzzy mathematics, Chen analysed the changes of vehicle rigid-body modes with speed, and the results showed that the frequency of the bogie hunting motion resonates with the carbody at a certain speed, leading to the low-frequency swaying [10]. However, there are few studies on the formation mechanism of vehicle low-frequency swaying; most researches are limited to describe its phenomenon and harm. So, it is necessary to explore the mechanism of vehicle low-frequency swaying to provide theoretical support for subsequent improvement and maintenance for the vehicle.

In view of this, this paper takes the lateral stability index of the metro vehicle as origin, which seriously exceeds the standard, carries out an experimental research on the metro vehicles which have abnormal vibration, establishes a vehicle dynamic model, and analyses the influencing factors about low-frequency swaying phenomenon. Exploring the causes of low-frequency swaying through the engineering application phenomenon on metro vehicles and the influence of the worn wheel rolling profile is not to be ignored, which is specifically reflected by causing vehicle hunting motion. Based on exploring the relationship between vehicle hunting and low-frequency swaying, the article studies the formation mechanism to explain the phenomenon of swaying and then clarifies the mechanism of the low-frequency vehicle swaying.

\section{Track Experimental Study on Low-Frequency Swaying}

During the later operation of the spin roller cycle, the lateral stability index of metro vehicles exceeds the standard; an obvious lateral swaying was observed when riding the vehicles, which affects the riding comfort seriously. Therefore, the special dynamic test about abnormal vibration of the vehicle was carried out; the sensors and data collectors come from HBM, which are used for measuring and collecting the vibration acceleration at each measuring point on the metro. Under normal operating load conditions, carbody, frames, and axleboxes are selected as research objects to measure the vibration acceleration signals. As the key parts of the vehicle, they are analysed with the running phenomenon in the whole line operation. Figure 1 shows the position of the acceleration sensor measurement points in the dynamic test on the metro bogie, the acceleration sensors, and data collectors.

Aiming at the lateral swaying phenomenon of carbody during driving, the short-time Fourier transform (STFT) is performed on the lateral acceleration vibration signal of carbody, frames, and axleboxes, which were measured in this dynamic test. We can obtain the time-frequency spectrum in whole line operation and determine the frequency component of lateral vibration when the carbody swaying and the transfer mode of the vibration between these parts, as shown in Figure 2, respectively, are the time-frequency diagrams about lateral vibration on carbody, frame, and axlebox in whole line operation. From these analysis results, it can be seen that a lateral vibration main frequency of about $2.5 \mathrm{~Hz}$ obviously exists on these parts when the vehicle is running at a constant speed. Selecting carbody as the research object, after intercepting and magnifying the timefrequency diagram between two stations, combined with the driving speed, as shown in Figure 3, it can be seen that when the speed reaches more than $80 \mathrm{~km} / \mathrm{h}$, the $2.5 \mathrm{~Hz}$ vibration of carbody is more obvious, it can be seen that the amplitude of vibration acceleration is greater than $0.02 \mathrm{~g}$ when the car is swaying, and it can reach $0.05 \mathrm{~g}$ in serious cases, which is far higher than the normal state about $0.01 \mathrm{~g}$. And the frequency of vibration does not change when speed changes, so this frequency is more likely to be a natural vibration frequency of the carbody. In addition, the lateral vibration of the carbody at about $2.5 \mathrm{~Hz}$ is not obvious at low speed.

According to the evaluation of the stability index shown in Figure 4, the lateral and vertical stability indexes both exceed the limit 2.5 when swaying, which are considered excellent when calculated by the Sperling method below 2.5, but according to the lateral acceleration criterion at frameend, the bogie did not exceed the alarm limit at this moment, and by performing $0.5-10 \mathrm{~Hz}$ band-pass filtering analysis on the lateral acceleration of frame-end, the maximum value is $0.67 \mathrm{~g}$, having not reached the limit value $0.8 \mathrm{~g}$ in 6 consecutive times, so the vehicle stability meets the requirement under this speed at this time $[11,12]$.

As shown in Figure 5(a), a $40 \mathrm{~Hz}$ low-pass filtering analysis is carried out on the lateral vibration acceleration of the carbody, and the lateral stability index of the vehicle is calculated. It can be seen from the whole line operation that the lateral vibration acceleration of the carbody is within the range of $0.1 \mathrm{~g}$, and the stability index is within the superior level 2.5 approximately at most of the time. However, the maximum lateral vibration of the carbody can reach $0.18 \mathrm{~g}$ in some time periods. At this time, the lateral stability index is the largest, which can reach 3.2, greater than the qualified standard 3.0. Then select the lateral acceleration of the carbody when the lateral stability exceeds the limit for magnifying analysis; the result is shown in Figure 5(c). And we can see that the harmonics in the lateral vibration are obvious, which indicates that the carbody is unstable and manifested as lateral swaying.

Similarly, after performing a $40 \mathrm{~Hz}$ low-pass filtering analysis, a band-stop filter of $2-3 \mathrm{~Hz}$ is carried out to compare the impact of vibration between 2 and $3 \mathrm{~Hz}$ on the vibration characteristics of the vehicle, and the lateral 


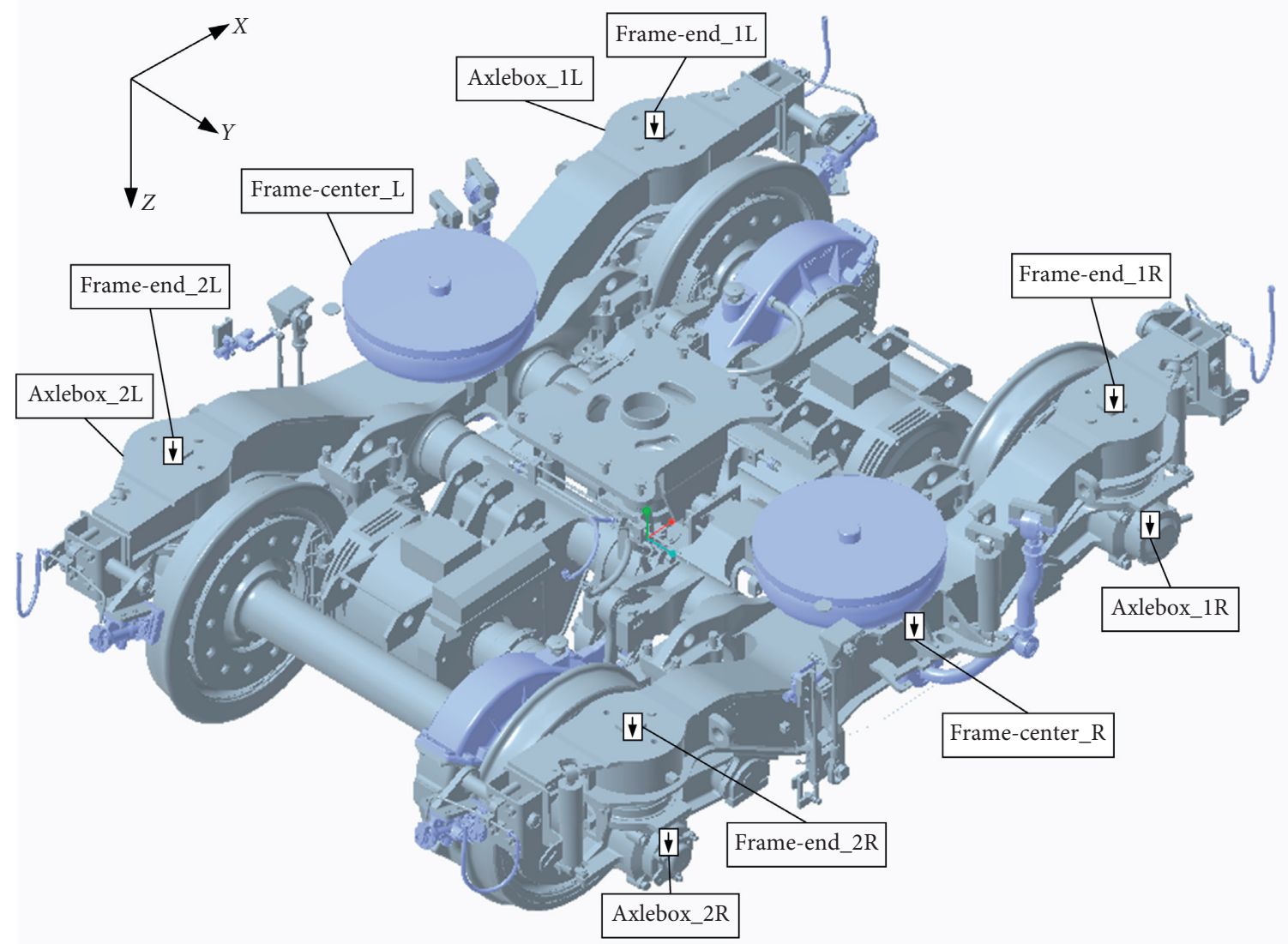

(a)

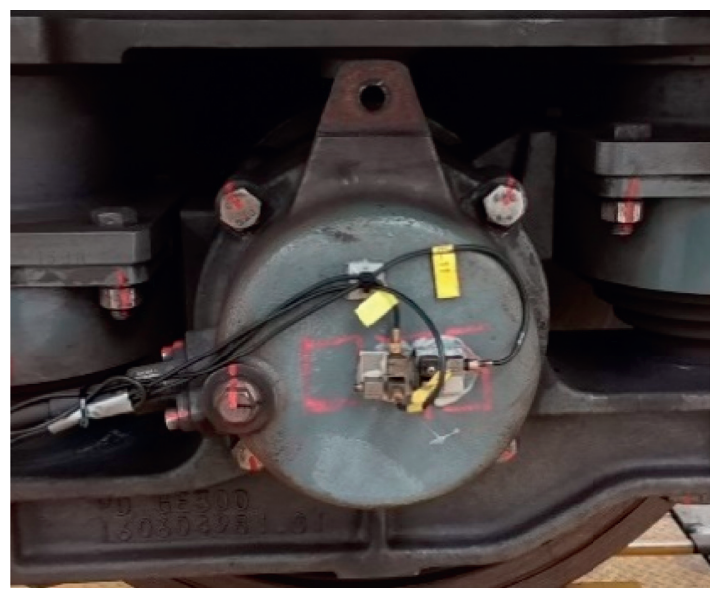

(b)

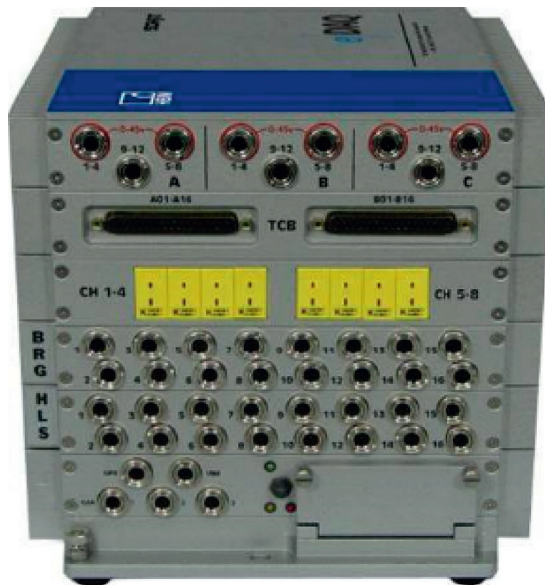

(c)

Figure 1: Acceleration sensor measurement points for dynamic test on metro bogie. (a) Measurement points of acceleration sensor on bogie. (b) Acceleration sensor on axlebox. (c) Data collector.

stability index is calculated at the same time. It can be seen in Figure 5(b) that the amplitude of lateral acceleration is reduced significantly, with the maximum value of around $0.12 \mathrm{~g}$. The lateral stability of the carbody is 2.68 , which is 0.52 lower than the value in Figure 5(a) obviously. Then, select the lateral acceleration of the carbody when the lateral stability exceeds the limit for magnifying analysis; the result is shown in Figure 5(c); there are no significant harmonics in the time domain. From the comparing results, it can be determined that the lateral vibration of about $2.5 \mathrm{~Hz}$ has a significant impact on the lateral stability of the carbody, which is also an important reason for the low-frequency swaying. Because the low-frequency swaying phenomenon occurs when the speed is higher than $80 \mathrm{~km} / \mathrm{h}$, but not obvious at low speed, it can be determined that the problem of low-frequency swaying is due to the natural mode of the 


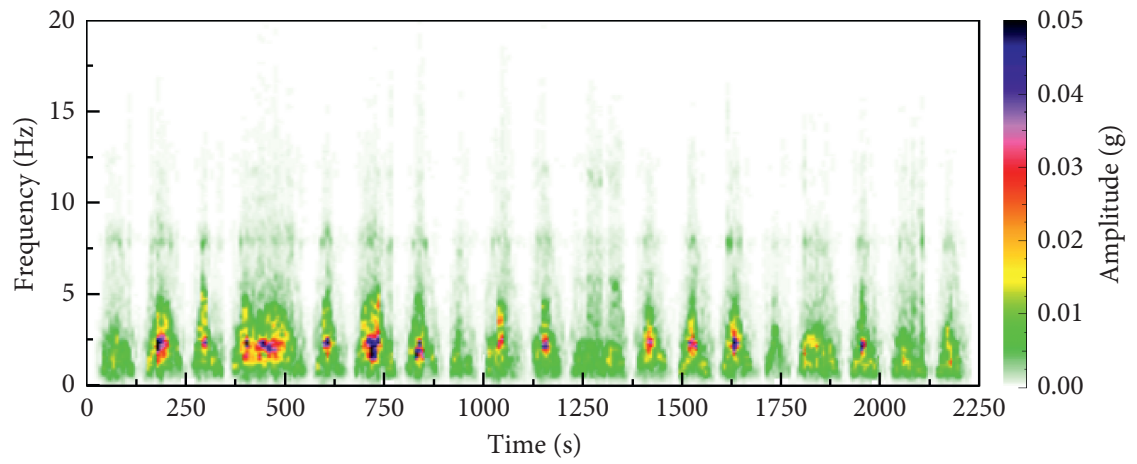

(a)

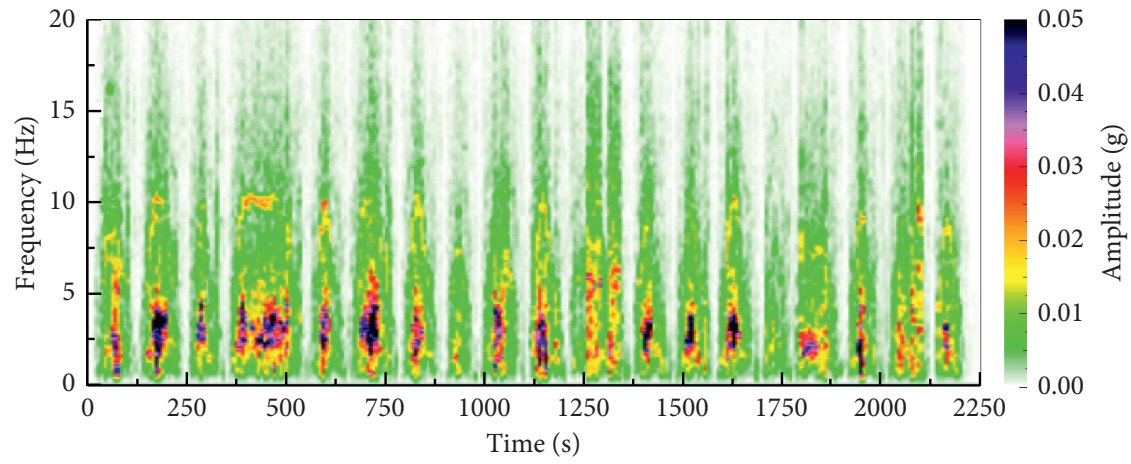

(b)

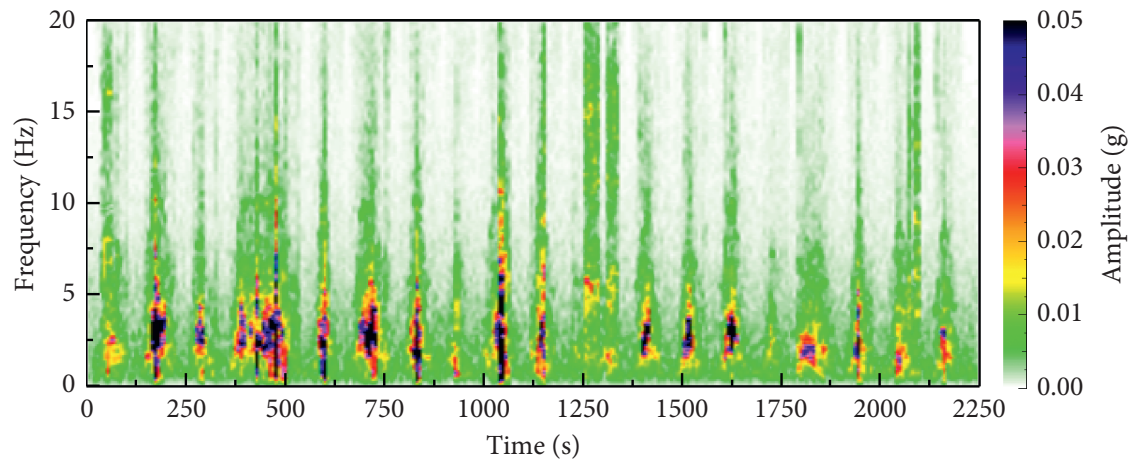

(c)

FIgURe 2: Time-frequency analysis of lateral vibration acceleration on carbody, frame, and axlebox (All). (a) Left side on carbody above the first bogie. (b) Left side on frame-end of the first bogie (Frame-end_1L). (c) Left axlebox of first axle (Axlebox_1L).

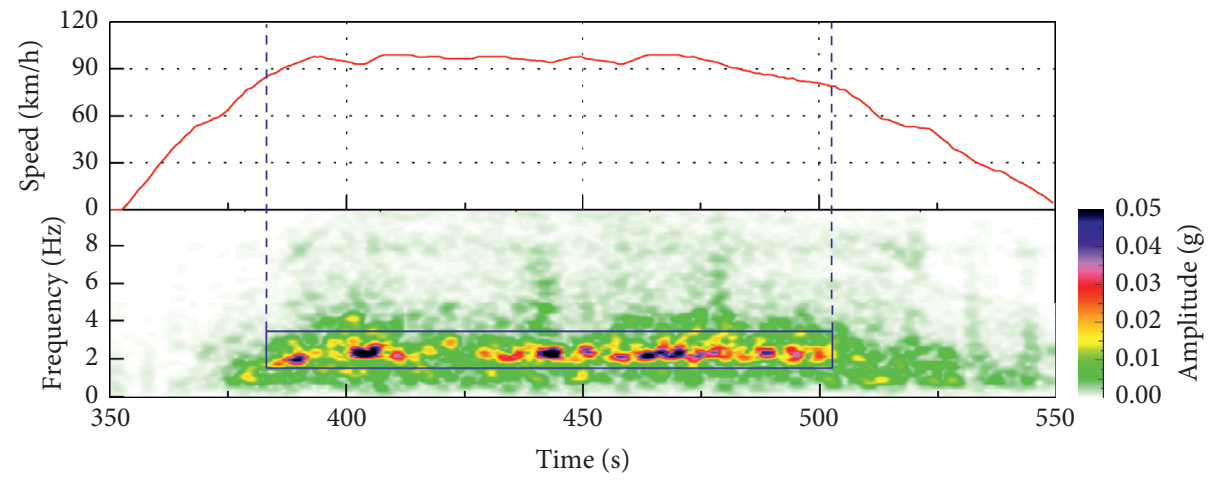

FIGURE 3: Time-frequency diagram about carbody and speed of vehicle (part). 


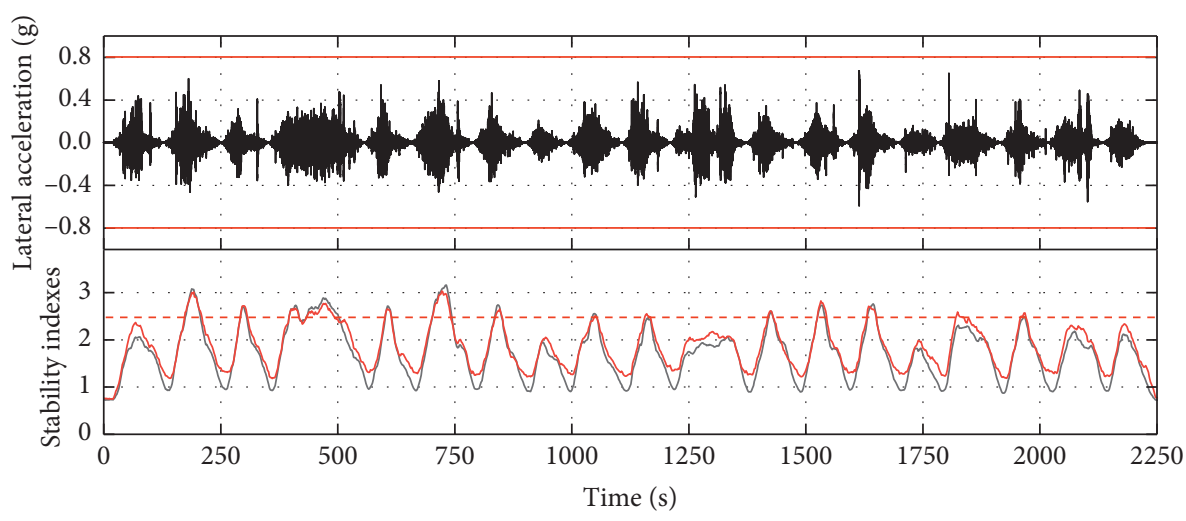

- Frame-end

— Lateral stability

— Vertical stability

Figure 4: Stability indexes and lateral acceleration at frame-end.

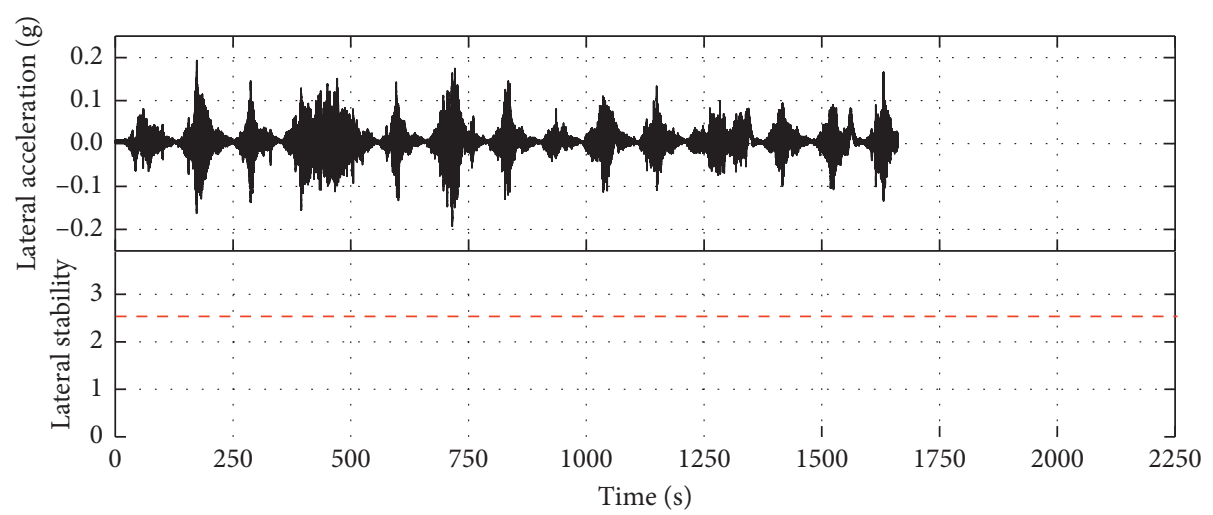

__ Left side above first bogie of carbody

(a)

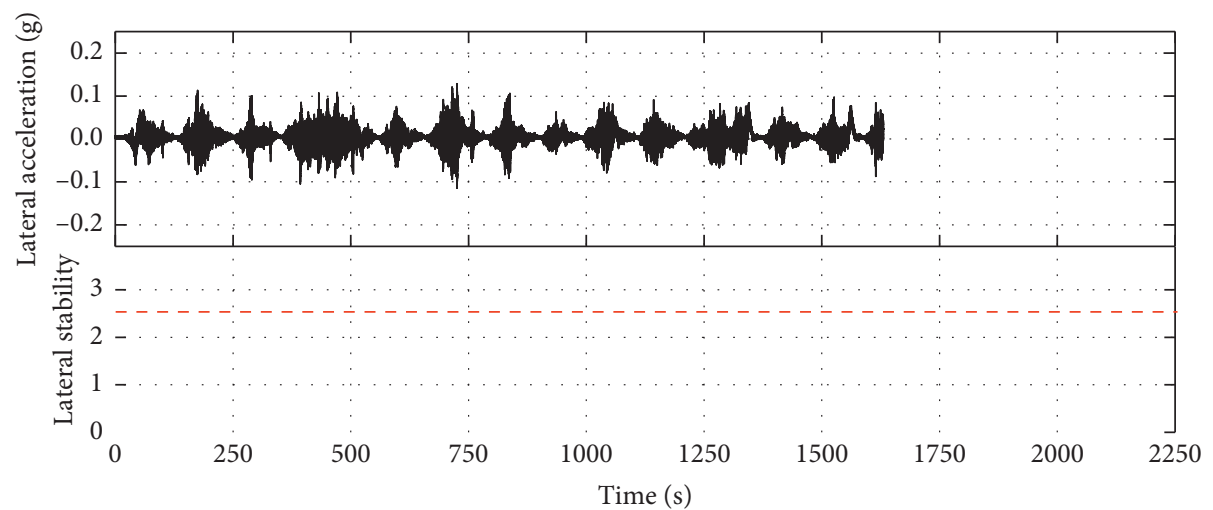

_ Left side above first bogie of carbody

(b)

Figure 5: Continued. 


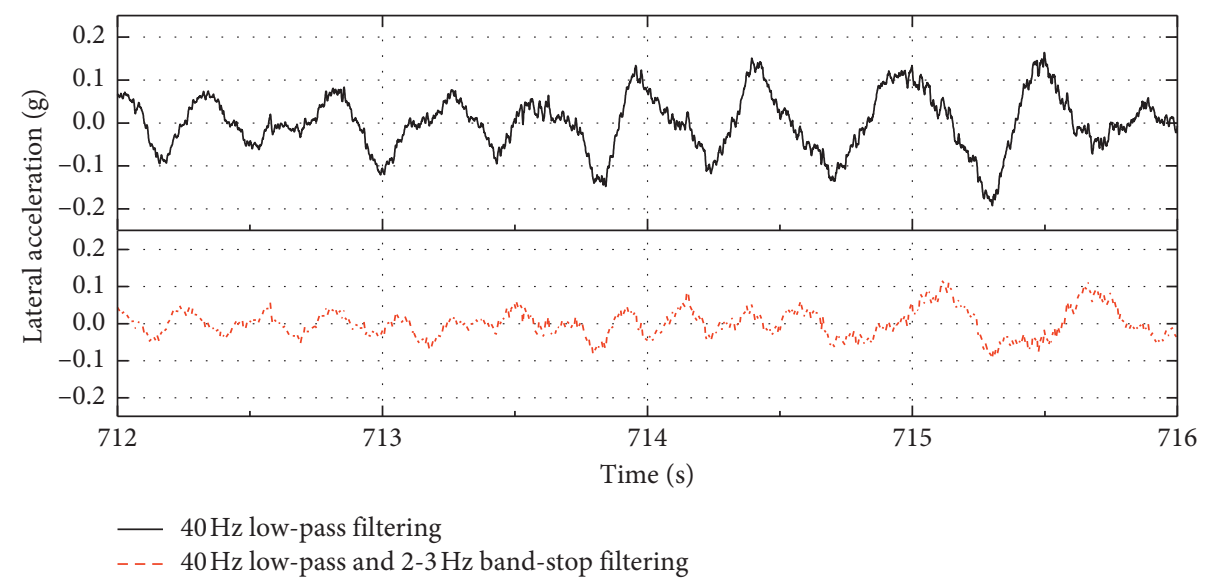

(c)

Figure 5: Time-domain analysis of lateral vibration acceleration and stability index of carbody. (a) $40 \mathrm{~Hz}$ low-pass filtering (all). (b) $40 \mathrm{~Hz}$ low-pass and 2-3 Hz band-stop filtering (all). (c) Time-domain amplification of carbody lateral vibration (part).

carbody which is excited by the disturbances when the vehicle is running at high speed, and the excitation frequency is related to the speed.

\section{Cause Analysis of Vehicle Swaying}

3.1. Analysis of Excitation Source. Based on the vehicle swaying phenomenon, from the analysis of line test results, the problem of low-frequency swaying is that the natural mode of the carbody is excited due to the disturbance when being at high-speed running, so the source of the disturbance needs to be determined and studied. There are many disturbance sources that affect the vehicle dynamic performance, mainly including the forced vibration caused by dynamic imbalance of wheelset, the forced vibration caused by track plate length, the vibration caused by rail length, and the hunting motion of bogie $[13,14]$. Among them, the vibrations caused by dynamic imbalance of wheelset, track plate length, and rail length mainly affect the vertical performance of the vehicle, but rail length also affects the lateral performance, such as the hunting motion of bogie $[15,16]$.

Due to a certain relationship between the low-frequency swaying phenomenon and driving speed, rail length online is constant, so the influence of rail length can be eliminated. The low-frequency swaying phenomenon mainly occurs in the later abrasion period; therefore, the main reason for the abnormal lateral vibration of the vehicle should be the hunting motion of the bogie. For the wheels of test metro, the main disturbance frequencies are shown in Figure 6 calculated based on speed.

3.2. Wheel-Rail Contact Relationship and Hunting Motion of Vehicle. The main factors that affect the hunting motion frequency of bogie are the suspension parameters and the wheel-rail contact relationship. In the actual lines, the equivalent conicity of wear wheel is generally higher when it is matched with new rail, and the vehicle is more likely to have bogie hunting motion rather than carbody hunting motion $[17,18]$. However, the test results show that carbody hunting motion occurs in some parts of the line sections, which indicates that the wheel-rail contact geometry of the line sections has significantly changed, causing the lateral swaying of the carbody.

Equivalent conicity is an important index that represents the geometric contact relationship between wheel and rail. It is the functional relationship between the radius of wheel rolling circle and wheelset lateral displacement, which has a great influence on the critical speed of the vehicle system, known as the critical hunting speed, the vehicle starts to have hunting motion at this speed $[19,20]$. In the upper part of Figure 7(a), there is the surface profile of rail where vehicles' swaying occurs during operation and the surface profiles of standard CN60 rail, called measured rail surface and standard rail surface, and the rail cant is $1: 40$. In the lower part of Figure 7, there is a comparison of the rail wear depth between these two rail surfaces. Figure 7(b) contains the wheel tread profiles at the top and the wheel wear depth at the bottom; the measured wheel tread comes from the vehicle which makes swaying; the standard wheel tread comes from the new LM wheel. By analysing the wear depth of the wheel tread and rail surface, it can be seen that the maximum wear depth of the left rail is $1.443 \mathrm{~mm}$, the left rail is $1.804 \mathrm{~mm}$, the wear depth of the left wheel is $1.892 \mathrm{~mm}$, and the wear depth of right wheel is $1.571 \mathrm{~mm}$ in maximum. Then we can make sure that the measured rail surface and wheel tread are worn seriously, which must have a great impact on the wheel-rail contact relationship of the vehicle.

Then matching standard rail surface and measured rail surface with standard wheel tread and measured wheel tread. Four different wheel-rail contact relationships are obtained, and the equivalent conicities are shown in Figure 8. It can be seen from the figure that the equivalent conicity is not greatly affected by the wear of rail surface, but the wear of wheel tread. When standard wheel tread is matched with standard rail surface and measured rail surface, the equivalent conicities do not change significantly within $7 \mathrm{~mm}$ of the wheelset lateral displacement. But when the measured tread is matched with these two rail surfaces, the equivalent 


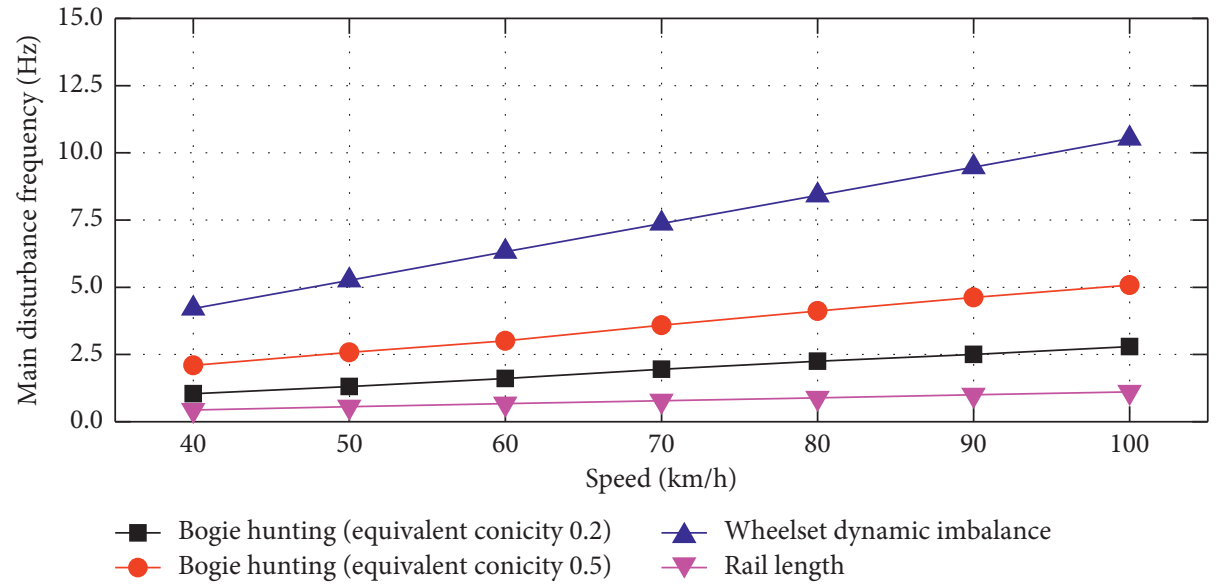

Figure 6: Main disturbance frequency of test metro.
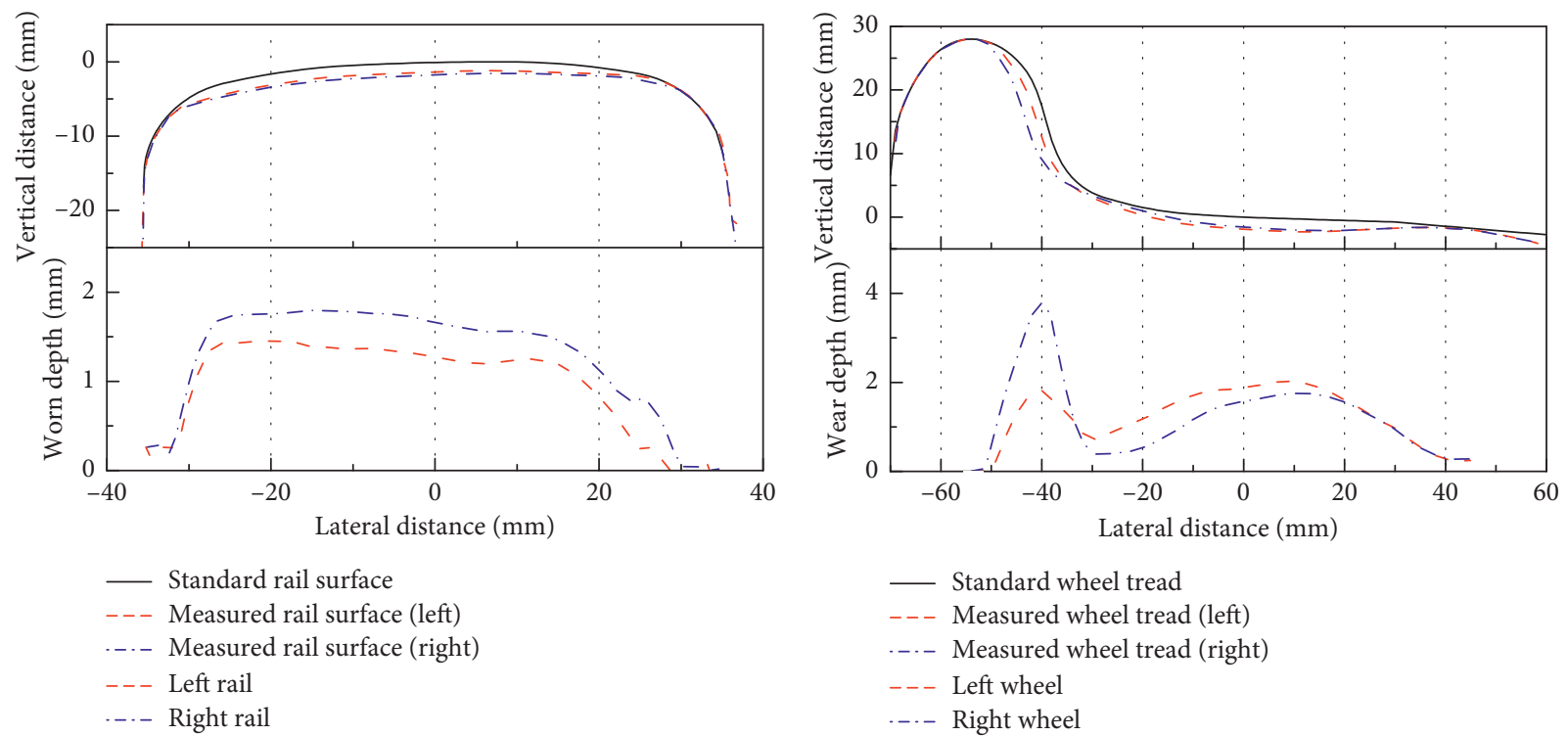

(a)

(b)

FIGURE 7: Measured surface and wear depth about rail and wheel. (a) Rail surface at swaying position. (b) Wheel tread about swaying vehicle.

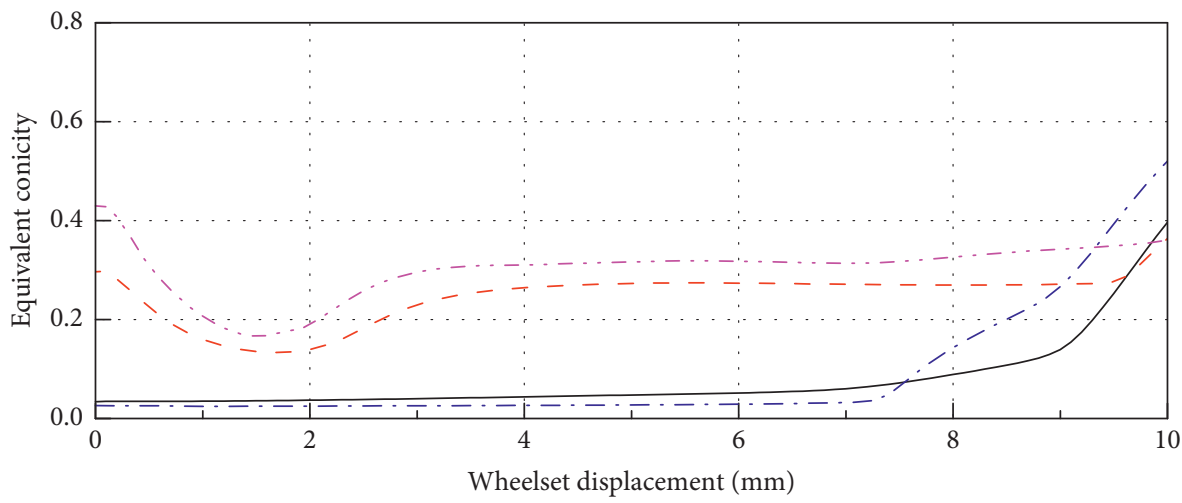

Standard rail - standard wheel

-..- Measured rail - standard wheel

- - Standard rail - measured wheel

Measured rail - measured wheel

FIGURE 8: Four kinds of wheel-rail matching equivalent conicity. 
conicities have a relatively large initial value, above 0.3 . It gradually decreases as the wheelset lateral displacement increases at the beginning and reaches a minimum value at about $1.5 \mathrm{~mm}$, then increases, and is stabilized near 0.3 when the wheelset lateral displacement reaches $3.5 \mathrm{~mm}$.

\section{Multibody Dynamics Simulations and Mechanism Study}

Metro vehicle is a complex multibody system, mainly constituted by carbodies, bogies, wheelsets, and suspension systems. During operation, each component of the vehicle generates severe vibration and is coupled with its own natural vibration, thus exhibiting strong nonlinearity and time variability [21]. The suspension systems and the wheelrail contact relationships are also nonlinear at the same time. Therefore, a full-vehicle multibody dynamic simulation model is established to recreate the low-frequency swaying phenomenon of the carbody, and then the mechanism of the swaying problem is studied based on this model.

4.1. Nonlinear Processing in Vehicle Models. In the study of a nonlinear wheel-rail relationship, wheel-rail contact geometric parameters are considered as nonlinear functions of wheelset transverse displacement, including wheel rolling radius, wheel cross-section curvature radius, contacting angles, wheelset roll angles, and railhead cross-section curvature radius. Since the wheel and rail can have any shape, it is difficult to directly express the geometrical parameters of wheel-rail contact as an explicit function of the wheelset displacement, which can only be expressed as a numerical table of the wheelset displacement, while the intermediate values are calculated by linear interpolation method.

Figure 9 shows the 4 different wheel-rail contact geometry relationships, the numbers in the figures represent the equivalent conicity, 0 represents the initial wheel-rail contacting point, the negative numbers represent the lateral wheelset displacement at left, and the positive numbers represent the lateral wheelset displacement at right. Table 1 shows the equivalent conicities about them when the wheelset lateral displacement is $3 \mathrm{~mm}$ under the UIC519 standard. It can be seen that the equivalent conicities have a large difference between the measured tread and standard tread when matching the same rail surface, but closer when the same tread matches with two rails; the main reason is the wear depth of the wheel tread.

About the nonlinear wheel-rail interaction, the Kalker nonlinear creep theory was used to calculate the creep force between the wheel and rail, and then the lateral force and shaking moment of the rail on the wheelset can be obtained through iterative calculation. The scaling factor of the Kalker coefficient is 1.0 and the sliding friction coefficient between wheel and rail is 0.3 , using the force elements which have nonlinear characteristics to show the nonlinear suspension force. For example, the suspension lateral bump stop has a nonlinear stop characteristic, and the relationship between force and vibration displacement is shown in Figure 10.
4.2. Vehicle Dynamics Modelling and Analysis Methods. The vehicle system model is the basis of dynamics analysis and the theoretical basis for studying vehicle dynamic interactions; it is also the necessary foundation for further establishing the vehicle system dynamics model. According to the type of actual metro vehicle, a typical topology model is established, as shown in Figure 11.

When the relative displacement and speed between each part of the vehicle system are generated, it will cause the suspension system to generate forces and moments. The expressions of forces will be very complicated when being accurately solved, and there is no great need for the mechanism research. Therefore, the nonlinear force elements are simplified and linearized, so the differential equations for vehicle systems can be written in matrix form as follows:

$$
\mathbf{M} \ddot{y}+\mathbf{C} \dot{y}+\mathbf{K} y=0 .
$$

In the formula, $\mathbf{M}, \mathbf{C}$, and $\mathbf{K}$ are inertia matrix, damping matrix, and stiffness matrix of the system, 27-order matrices, and $y$ is the freedom degree vector of the system. Make $x_{1}=$ $y$ and $x_{2}=\dot{y}, \mathbf{E}$ is 27-order unit matrix, and reduce the linear differential equations order of the vehicle system:

$$
\dot{\mathbf{x}}=\left[\begin{array}{c}
\dot{x}_{1} \\
\dot{x}_{2}
\end{array}\right]=\left[\begin{array}{cc}
\mathbf{0} & \mathbf{E} \\
-\frac{\mathbf{K}}{\mathbf{M}} & -\frac{\mathbf{C}}{\mathbf{M}}
\end{array}\right]\left[\begin{array}{l}
x_{1} \\
x_{2}
\end{array}\right]=\mathbf{A}\left[\begin{array}{l}
x_{1} \\
x_{2}
\end{array}\right]=\mathbf{A x} .
$$

Due to the symmetrical structure of the vehicle system, the freedom degree is $m$, making $n=2 m$, when $x=0$ is the equilibrium position of the system. The differential equation of the nonlinear vehicle system is

$$
\mathbf{M} \ddot{y}+\mathbf{F}(\dot{y}, y, v)=0 .
$$

Reduced order $\dot{x}=f(x, v)$ and nonlinear function $f$ represents the nonlinear factors of vehicle systems, such as the nonlinear suspension force element and nonlinear wheel/rail contact relationship; expand the equations using Taylor formula:

$$
\dot{\mathbf{x}}=\mathbf{A}(\mathbf{v}) x+\mathbf{B}(x)
$$

When $\|x\| \longrightarrow 0$, the first approximation equation can obtain

$$
\dot{\mathbf{x}} \approx \mathbf{A}(\mathbf{v}) x=\mathbf{A} x .
$$

The matrix $\mathbf{A}(\mathbf{v})$ is an $n \times n$ order constant matrix and related to the speed $v$, and the Jacobian matrix is obtained:

$$
\mathbf{A}=\left[\frac{\partial f_{i}}{\partial f_{j}}\right]_{x=0}=(i, j=1,2, \ldots, n) .
$$

According to the stability theory of motion, the stability of the nonlinear vehicle system zero solution can be determined by studying the eigenvalues of the first approximate equations (5). For nonlinear vehicle systems, by obtaining the eigenvalues and eigenvectors of the Jacobian matrix $\mathbf{A}$, the modal frequency, modal damping, and modal shapes of the vehicle can be obtained. Using the linear 


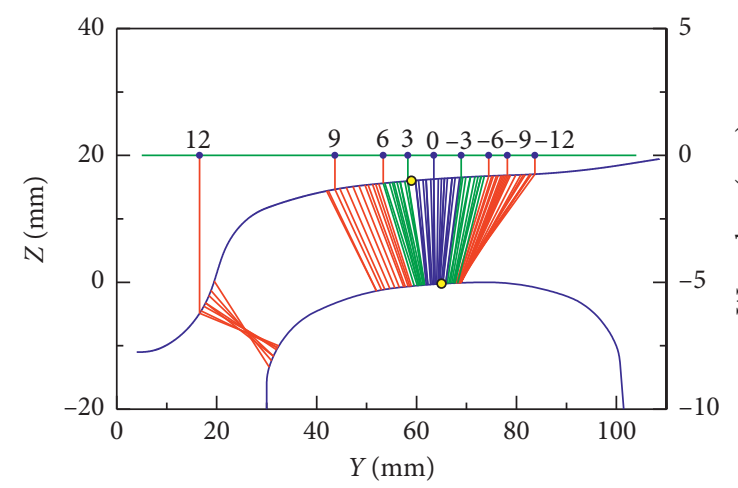

(a)

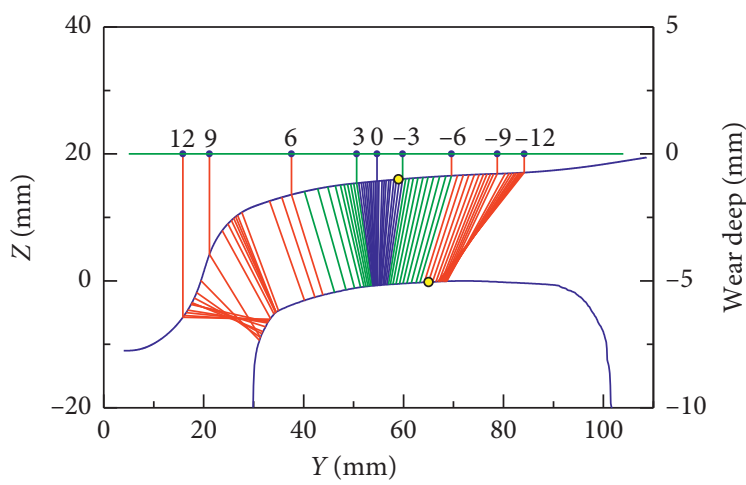

(c)

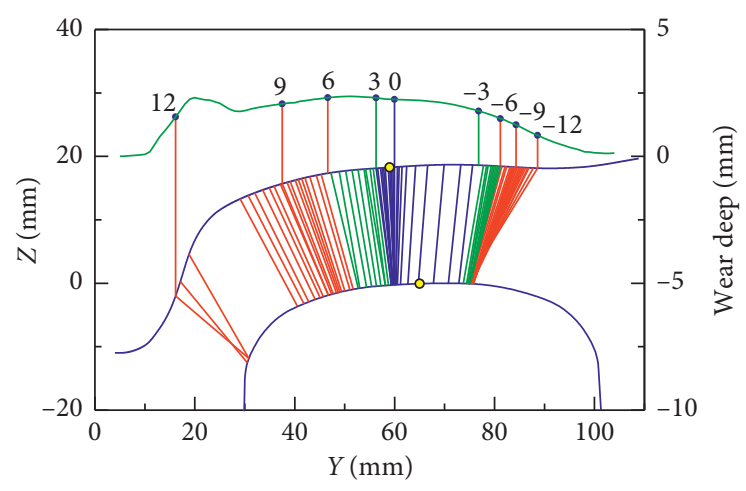

(b)

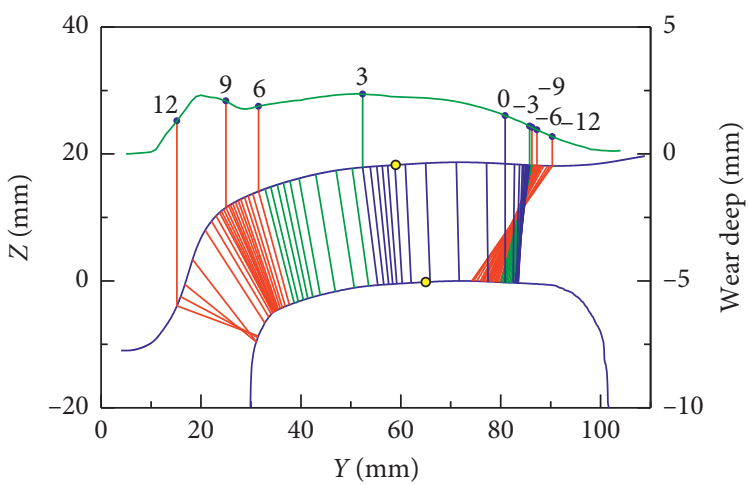

(d)

Figure 9: Wheel-rail contact geometry relationship. (a) Standard wheel and standard rail. (b) Measured wheel and standard rail. (c) Standard wheel and measured rail. (d) Measured wheel and measured rail.

TABLE 1: Four kinds of wheel-rail matching equivalent conicity.

\begin{tabular}{lcc}
\hline & Standard new wheel tread (LM) & Measured wear wheel tread \\
\hline Standard new rail surface (CN60) & 0.041 & 0.230 \\
Measured wear rail surface & 0.026 & 0.295 \\
\hline
\end{tabular}

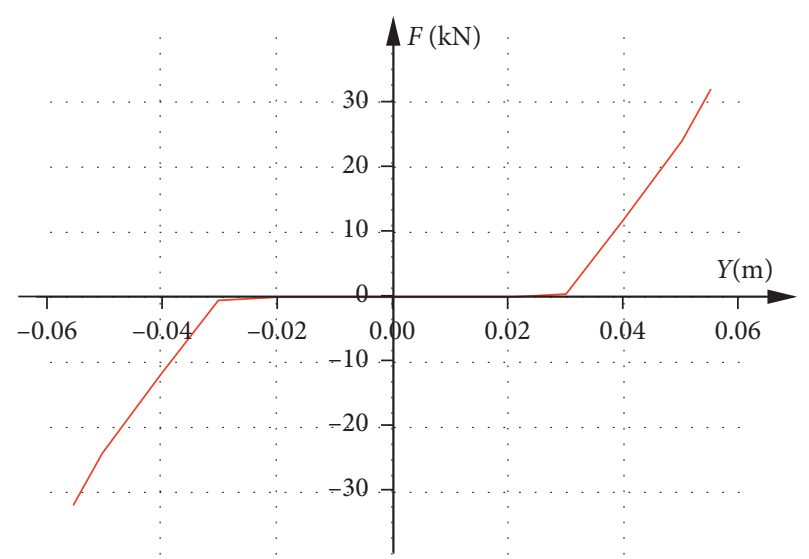

Figure 10: Nonlinear characteristics of lateral bump stop.

stability theory, the stability of the vehicle system can be determined by judging the real part of the eigenvalue. The suspension mode of the vehicle system will change when coupled vibration with hunting motion occurs, and the hunting motion mode changes with the speed and equivalent conicity; in certain cases, the hunting instability also occurs.

Taking the actual metro vehicle which makes swaying phenomenon as an example, using the multibody simulation software SIMPACK established a typical vehicle dynamics simulation model, as shown in Figure 12. This dynamics model is considered as a single-vehicle model instead of the train model. For the vehicle system, it consists of one carbody, two bogie frames, four wheelsets, and eight axleboxes, totally 15 rigid bodies, and the carbody and bogies are symmetric about a longitudinal plane of symmetry. Each carbody, frame, and wheelset have six independent freedom degrees which are longitudinal, lateral, and vertical translation and roll, pitch, and yaw movement; however, vertical and roll motion of wheelsets are coupled, and each axlebox has 1 freedom degree that is pitch movement, as shown in Table 2.

Because the flexible frequencies of wheels and rails are large, generally above $40 \mathrm{~Hz}$, which is much higher than the low-frequency swaying of the carbody, therefore, in the 


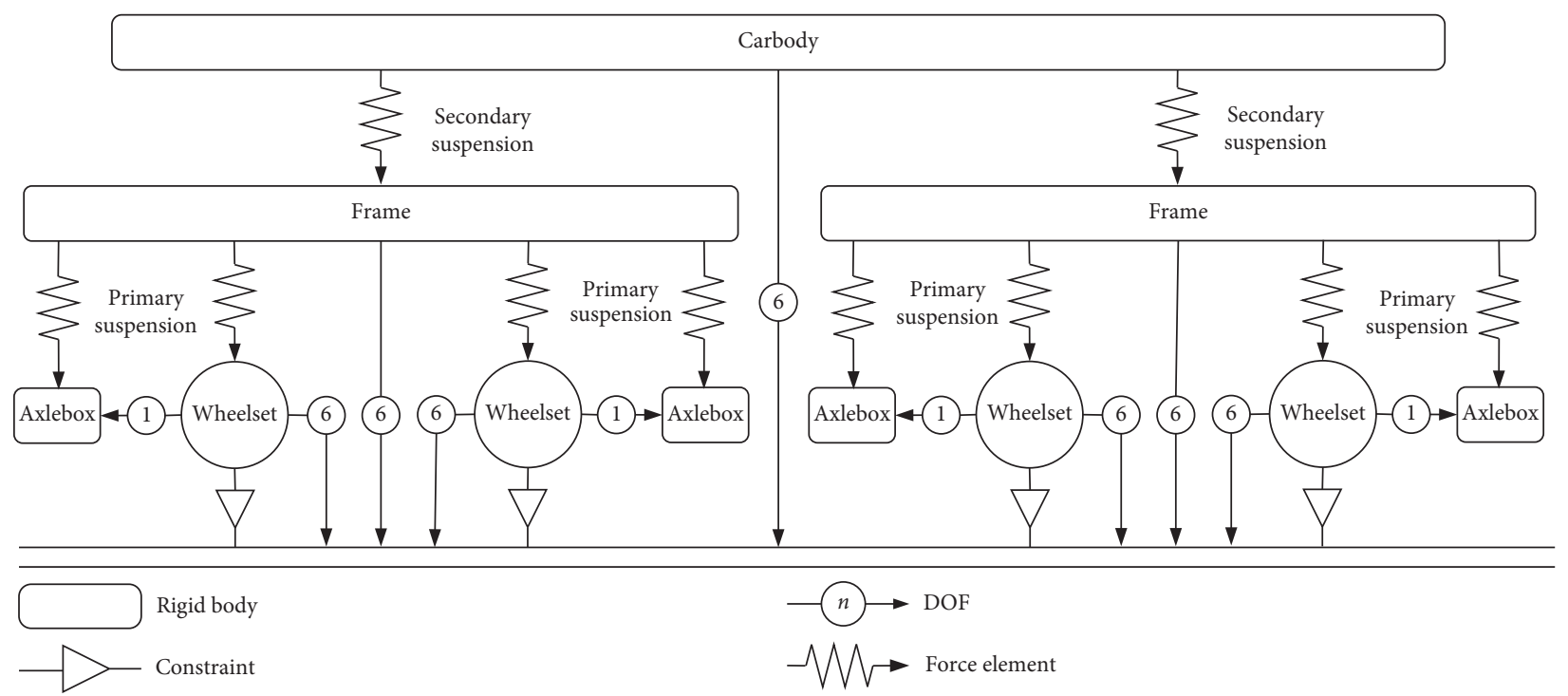

FIgURE 11: Topology model of metro vehicle.

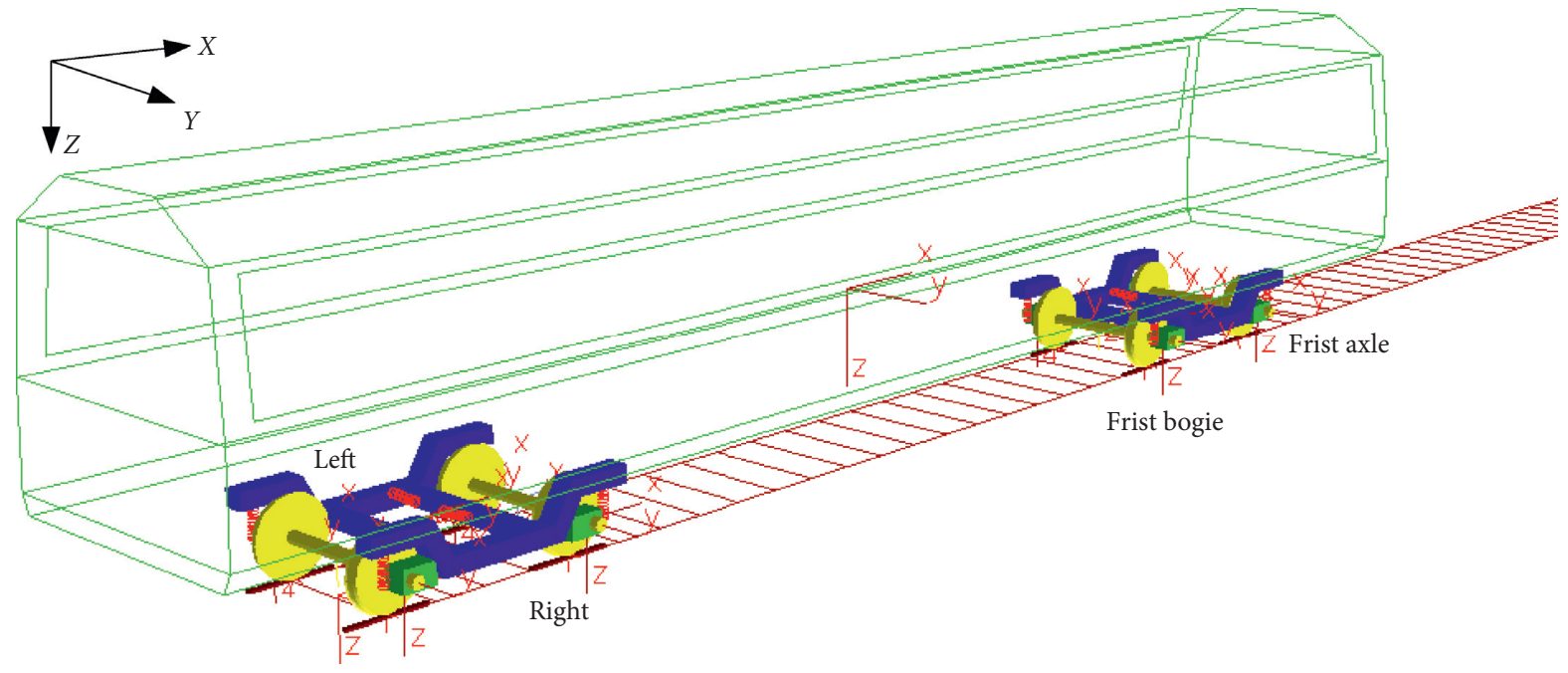

FIGURE 12: Vehicle dynamics simulation model.

TABle 2: Freedom degrees of vehicle dynamics model.

\begin{tabular}{lcccccc}
\hline $\begin{array}{l}\text { Freedom } \\
\text { degrees }\end{array}$ & Longitudinal & Lateral & Vertical & Roll & Pitch & Yaw \\
\hline $\begin{array}{l}\text { Carbody } \\
\begin{array}{l}\text { Frame } \\
(i=1,2)\end{array}\end{array} X_{\mathrm{c}}$ & $Y_{\mathrm{c}}$ & $Z_{\mathrm{c}}$ & $\phi_{\mathrm{c}}$ & $\psi_{\mathrm{c}}$ & $\beta_{\mathrm{c}}$ \\
$\begin{array}{l}\text { Wheelset } \\
(i=1,2,3,4)\end{array}$ & $X_{\mathrm{f} i}$ & $Y_{\mathrm{f} i}$ & $Z_{\mathrm{f} i}$ & $\phi_{\mathrm{f} i}$ & $\psi_{\mathrm{f} i}$ & $\beta_{\mathrm{f} i}$ \\
\hline
\end{tabular}

dynamic simulation model, the wheels and rails are considered as rigid bodies but not flexible bodies, which is helpful to clarify the mechanism [19]. In order to study the effect of wheel-rail equivalent conicity on the stability of the vehicle system, four kinds of wheel-rail matching relationships are used as research objects for dynamic simulation analysis, and the mechanism of low-frequency swaying is studied from mode coupling about carbody. That is, the measured wear rail surface, the standard CN60 rail surface, the measured wear wheel tread, and the standard LM wheel tread are imported into the model as the profile of the rails and wheels to simulate 4 different wheel-rail contacting relationships. Meanwhile, the track irregularity spectrum is the selected American track spectrum of 5th grade.

4.3. Wheel-Rail Equivalent Conicity and Vehicle Vibration Simulation. When the vehicle model is simulated, the FASTSIM program is used for calculation and solution in the wheel-rail contact model, which is compiled according to Kalker simplified theory; its calculation speed is very fast and can meet the high enough engineering precision and the requirements of numerical simulation analysis of vehicle dynamics. The data of four kinds of wheel-rail contact relationships are imported into the dynamic simulation analysis, in order to correspond to the line test data; the 
speed of the simulation model is set as $110 \mathrm{~km} / \mathrm{h}$ more than $80 \mathrm{~km} / \mathrm{h}$; then we can obtain the lateral vibration acceleration of carbody in time history under each condition. Through the analysis of the wheelset displacements in simulation results, within the speed range of the study, the maximum is $7.6 \mathrm{~mm}$, much less than $12 \mathrm{~mm}$, as shown in Figure 13. In this process, the wheelset will not smash the interior flanks with rail, so double contact or multicontact will not occur.

As shown in Figure 14, it can be seen that the lateral vibration acceleration of carbody when the standard tread matches the two rail surfaces is no more than $0.1 \mathrm{~g}$. When the measured tread matches the two rail surfaces, that is, the vibration acceleration increases to $0.2 \mathrm{~g}$ under the wheel-rail relationship with a larger equivalent taper, at this time, obvious vibration harmonics can be observed through local amplifying signals.

By performing Fourier transform on the lateral vibration acceleration signal of the carbody, the main frequency of lateral vibration under the working condition can be obtained, as shown in Figure 15. The comparison shows that when the standard tread is matched with the two rail surfaces, the main frequency of lateral vibration is not obvious, and the vibration amplitude at $2.5 \mathrm{~Hz}$ is small, but obviously when the measured tread is matched with the two rail surfaces, and the vibration amplitude is large, which is close to the main frequency obtained by the line test. Similarly, the lateral vibration acceleration and the vibration frequency of the frames and axleboxes can be obtained, and the analysis results are also consistent with the line test. This can verify the influence of wheel tread wear on the wheel-rail contact relationship, increasing the equivalent conicity of wheel-rail contact which is the fundamental reason for carbody to generate low-frequency swaying around $2.5 \mathrm{~Hz}$.

\subsection{Vehicle Hunting and Modal Coupling Mechanism of} Carbody. For the vehicle systems, the instability modes are divided into restorative modes and permanent modes, and the upper swaying, lower swaying, and yaw modes of carbody are the restorative modes, while the bogie hunting is the permanent mode (Figure 16). When the hunting frequency of the bogie is close to the suspension frequency of carbody, under certain conditions, these two modes will be coupled and converted to each other [20].

Actually, the common speed range of the metro vehicle is $80-100 \mathrm{~km} / \mathrm{h}$. Figure 17 shows the hunting resonance with the natural frequencies at different equivalent conicities. At a low level, when the vehicle has carbody hunting motion, the speed is high which leads to resonance, while at a high level, the speed is low. When the wear wheels match the wear rails, the equivalent conicity becomes bigger, so the hunting motion resonance will occur at a lower speed which may fall in the common speed range.

The hunting stability of metro vehicle bogie is an inherent attribute of the system itself, and a key factor determining whether a vehicle can run safely. In the case of numerical simulation about the nonlinear model, the vehicle is supposed to pass over a track with an irregularity spectrum at a certain speed and then run on a smooth line. And check whether the lateral displacement of the wheelset converges to judge the stability of the vehicle. Figure 18 is the Hopf diagram; the limit cycle amplitude presents the lateral displacement of the first wheelset in stability, obtained by the speed-up method and speed-down method, respectively. From the stability characteristics on a straight track, it can be determined that the hunting motion belongs to the type of supercritical Hopf bifurcation.

During the deceleration process, when the speed is higher than $110 \mathrm{~km} / \mathrm{h}$, the vehicle system has a large amplitude hunting motion; as the speed decreases, the wheelset lateral displacement decreases; until the speed lower than about $87.5 \mathrm{~km} / \mathrm{h}$, the motion will converge to the balance, and the hunting motion will be in a small amplitude, less than $1 \mathrm{~mm}$. This point is a demarcation point for the appearance and disappearance of the equal-amplitude hunting, and its velocity is defined as the nonlinear critical velocity, which is the lowest critical velocity of the system and appears only under extreme orbital condition.

The root-locus method is a graphical method for analysing and designing the feedback control system; when one or more parameters in the closed-loop system change continuously from zero to infinity, the roots (closed-loop pole) of the characteristic equation move continuously on the root-plane and form loci. In a certain wheel-rail contact condition, the vehicle system model is linearized, assuming that the linearization equation is $d x / d t=\mathbf{A} x$, and the solution of the equation is expressed as $x(t)=\psi e^{\sigma t}$. In this equation, eigenvector $\psi$ represents the mode shape of each vibration, $\sigma$ represents eigenvalue, its real part represents the damping value of each mode, and the imaginary part represents the frequency of each mode determined by the equation $(\mathbf{A}-\sigma \mathbf{I}) \psi=0$. By transforming the real and imaginary parts of the eigenvalues, the vibration frequencies $f=\operatorname{Im}(\sigma) /(2 \pi)$ and damping ratios $\xi=-\operatorname{Re}(\sigma)$ of each mode can be taken [22, 23]. When the vehicle system damping ratio is greater than 0.05 , the system is stable and it is unstable when it is less than 0.05 .

The low-frequency swaying phenomenon of carbody is due to the increasing running speed, which causes the natural frequency of carbody to be excited, and the frequency of the disturbance is about $2.5 \mathrm{~Hz}$. Therefore, it is necessary to analyse the vibration mode of carbody. In order to correspond to the actual line test, the equivalent conicity of the wheel-rail contact relationship is set to 0.1 and 0.3 in the dynamic model, representing the standard wheel-rail contact and the measured wheel-rail contact, respectively.

Then the dynamic simulation is carried out through the root-locus method and the results are shown in Figure 19, the root-locus diagrams under two equivalent conicities. It can be seen that the frequency of pitch and lower swaying mode is not related to the running speed and wheel-rail equivalent conicity, basically, no change, and the frequency of bounce mode changes when the speed is low and tends to be stable with the speed is high, but the frequency of yaw, upper swaying, and hunting model change significantly with speed. By comparing the changing trend of carbody vibration mode under different equivalent conicity, it can be 


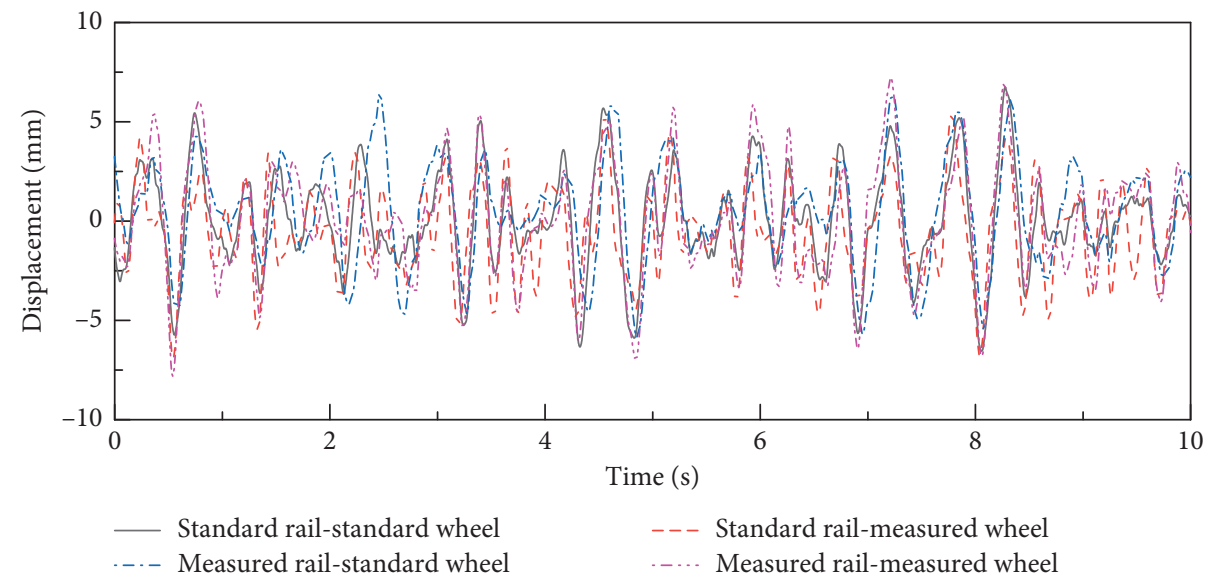

FIGURE 13: The lateral displacement of the first wheelset $(110 \mathrm{~km} / \mathrm{h})$.

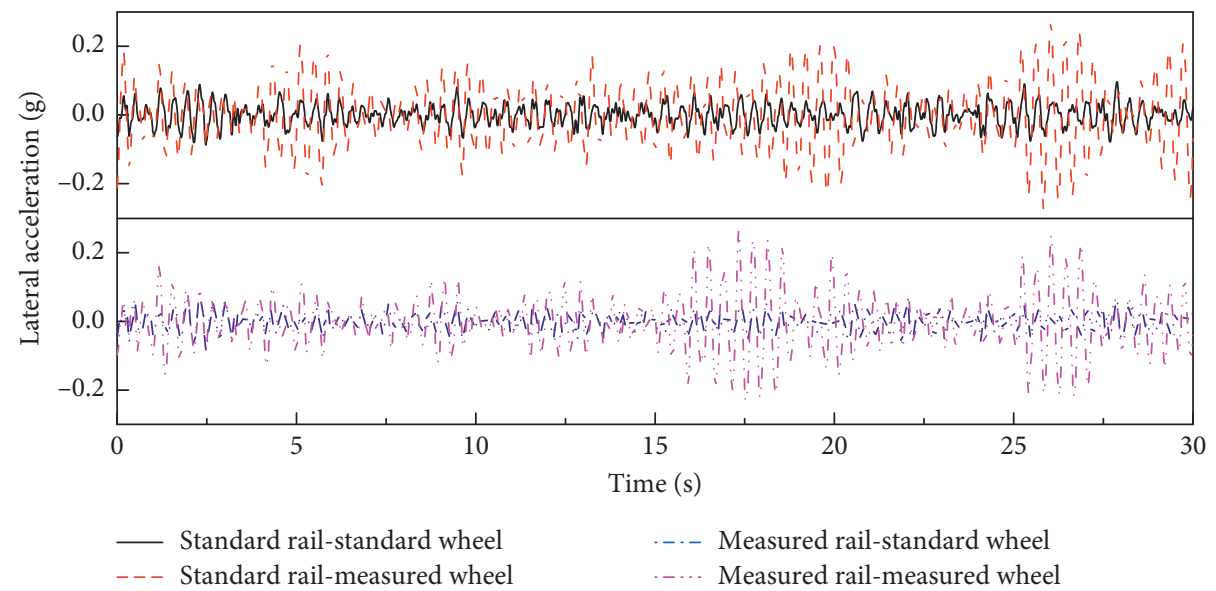

FIgURE 14: Time history comparison of vehicle body transverse vibration acceleration.

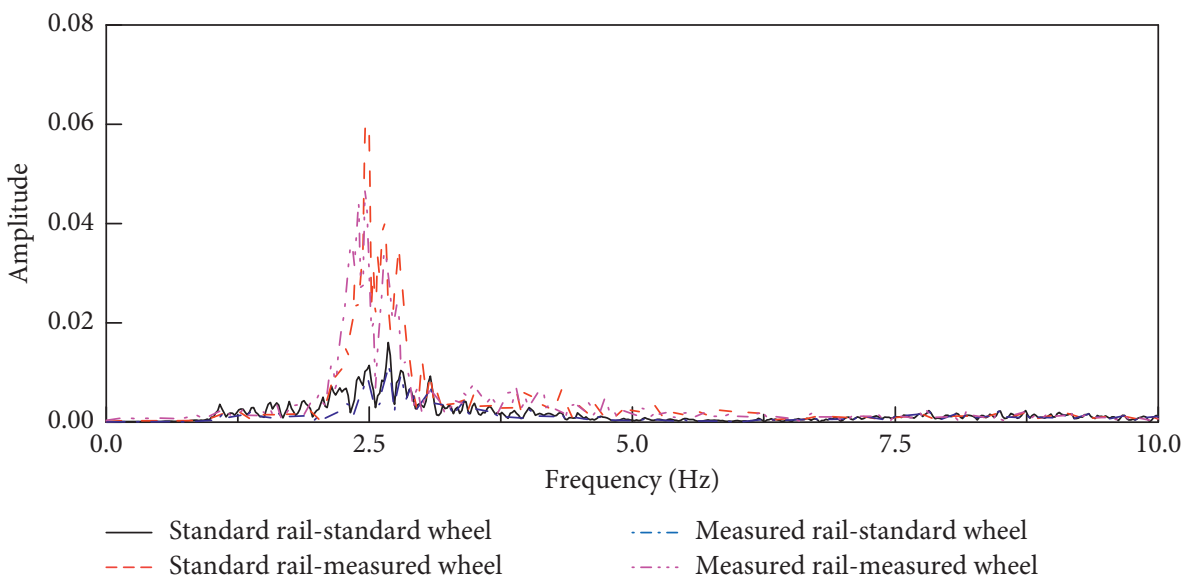

FIGURE 15: Comparison of the main frequency of vehicle body transverse vibration acceleration.

seen that when the equivalent conicity is 0.1 , the vibration shape of carbody such as yaw, upper swaying, and hunting changes in a small range, and the damping ratio of hunting does not exceed the critical range. When the equivalent conicity is 0.3 , the vibration modes of the carbody change dramatically with the speed, and when the speed reaches $80 \mathrm{~km} / \mathrm{h}$, the frequency of upper swaying is $2.5 \mathrm{~Hz}$, and having frequency conversion with hunting $\mathrm{A}$ at this time, the vehicle shows hunting motion. When the speed is close to $90 \mathrm{~km} / \mathrm{h}$ and the damping ratio of hunting motion drops to 


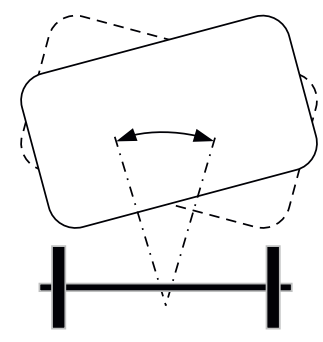

(a)

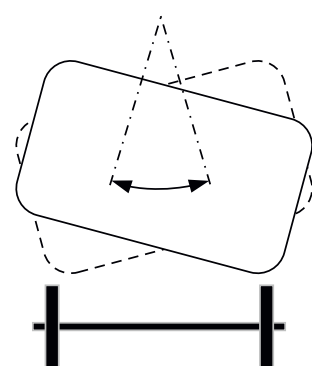

(b)

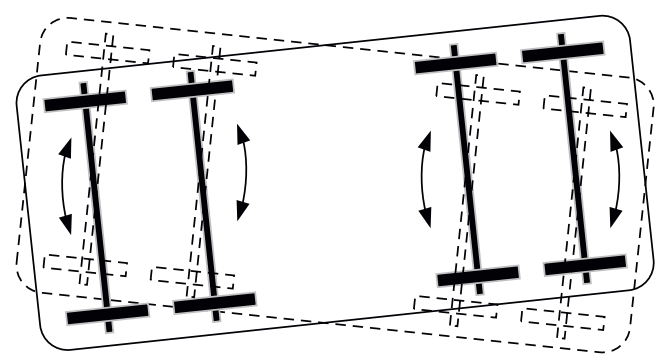

(c)

FIGURE 16: Lower swaying mode, upper swaying mode, and carbody hunting mode of the vehicle. (a) Lower swaying. (b) Upper swaying. (c) Carbody hunting.

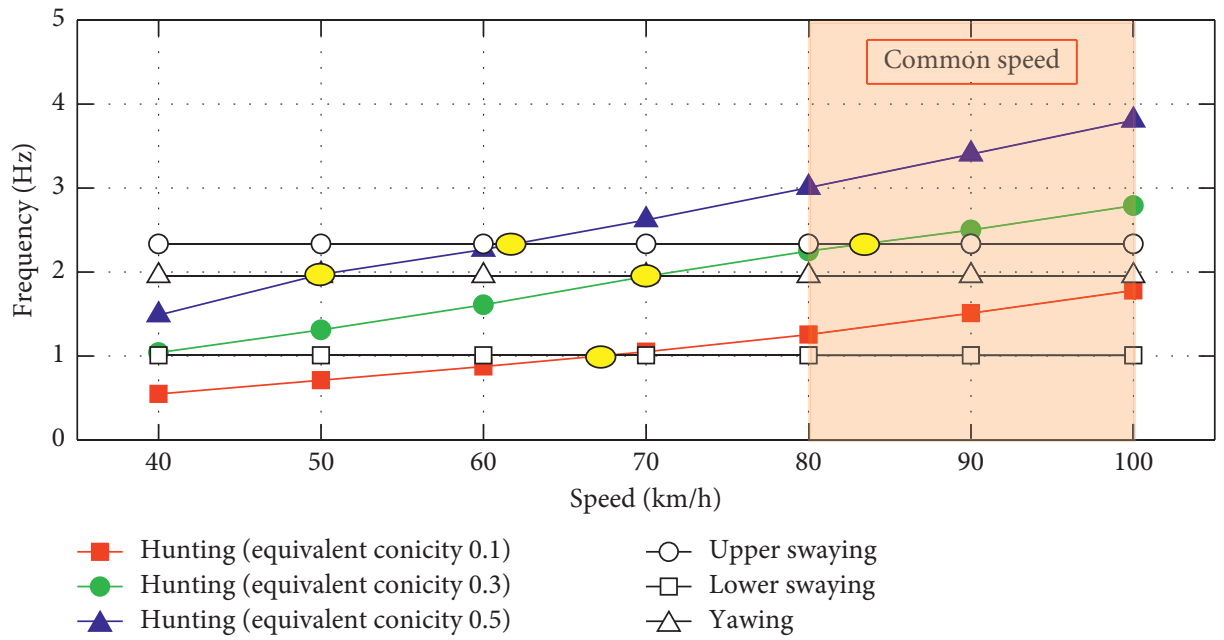

Figure 17: Resonance diagram at different equivalent conicities.

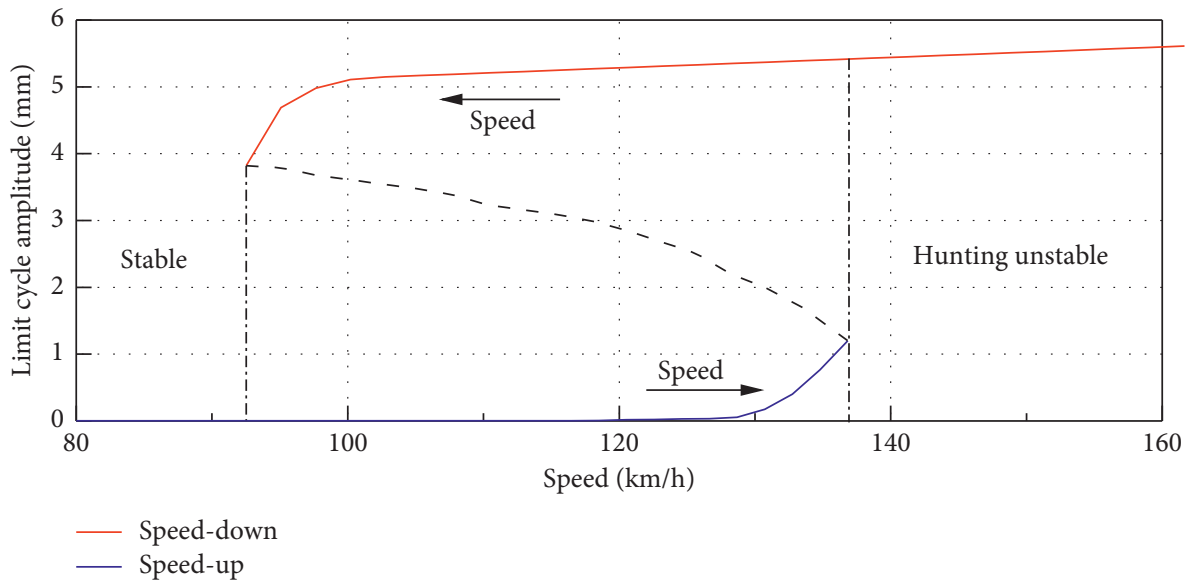

Figure 18: Hopf bifurcation diagram.

the critical value 0.05 , it can be judged that the vehicle shows hunting motion instability, which is similar to the phenomenon in the actual operation.

In summary, with the increasing of running speed and wheel-rail contact equivalent conicity, the damping ratio of the bogie hunting motion gradually decreases, and the frequency gradually increases, which will cause the bogie to make hunting motion. The upper swaying frequency of the carbody is $2.5 \mathrm{~Hz}$, which is the natural vibration mode; it does not change with speed and revenue length; however, it will make frequency conversion with the bogie hunting motion frequency and generate resonance phenomenon, which appears as the low-frequency swaying of carbody and causes the lateral stability index to exceed the standard. To 


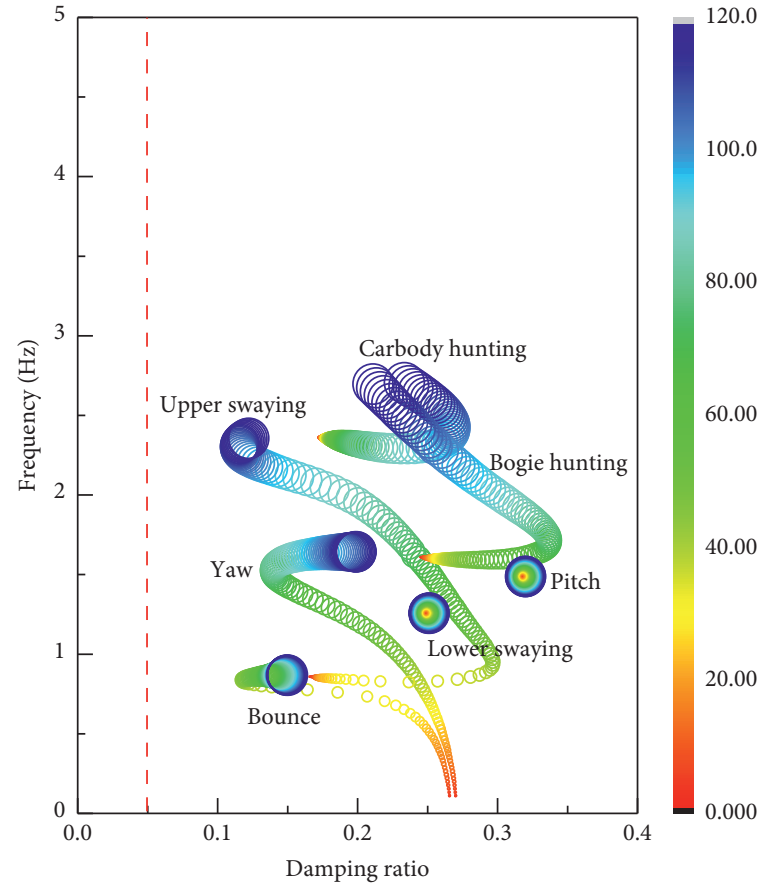

(a)

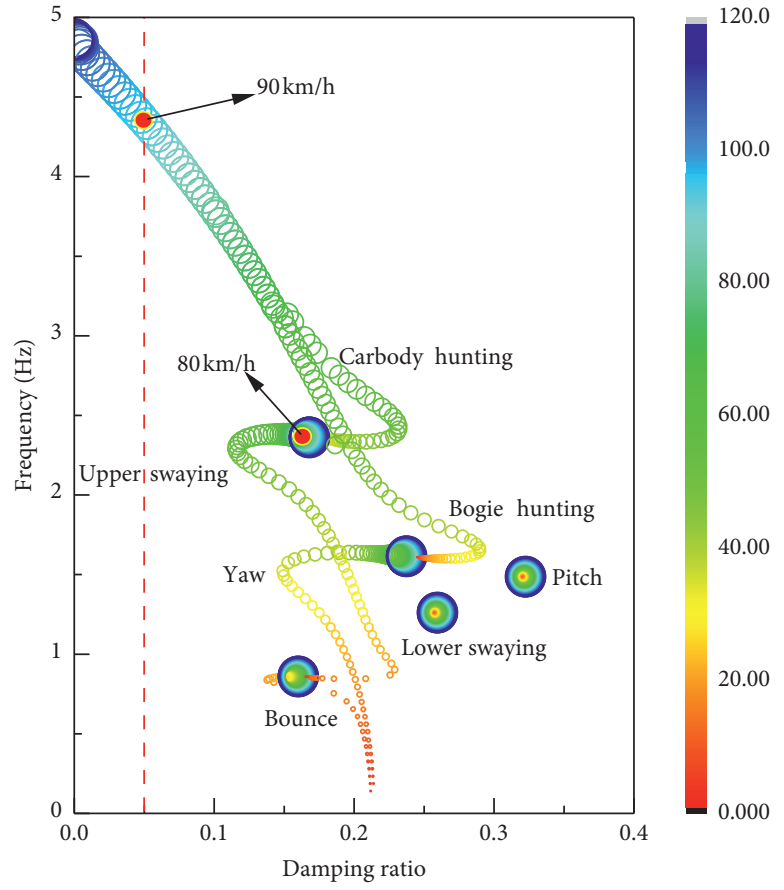

(b)

FIGURE 19: Root-locus diagrams of vehicle dynamic model simulation. (a) Equivalent conicity is 0.1. (b) Equivalent conicity is 0.3.

sum up, the low-frequency swaying phenomenon in the operation of metro vehicles is often caused by many factors, except polygon wheels, roll radii difference, resilient wheelset, and excessive hunting motion, which may also be caused by the increasing equivalent conicity of wheel-rail contact due to wheel wear.

\section{Conclusions}

There is an obvious phenomenon of carbody swaying when a railway metro vehicle was put into operation, and a dynamic test on the field was carried out. Test results show that there is a significant frequency of about $2.5 \mathrm{~Hz}$ on the carbody when the vehicle is passing certain sections of the railway line at a speed higher than $90 \mathrm{~km} / \mathrm{h}$. Furtherly, the vehicle system dynamics model is developed and the root-locus method is used to examine the natural frequency of the carbody. By comparing the field results and simulation results, conclusions can be drawn as follows:

(1) The low-frequency swaying of metro vehicles during long-term operation is the main reason for causing the vehicle stability index to exceed the limit, and the swaying frequency is approximately $2.5 \mathrm{~Hz}$.

(2) The worn rail profile has a little effect on the equivalent conicity of wheel-rail contact, but the wheel wear increases the equivalent conicity obviously.

(3) The carboy low-frequency swaying phenomenon is caused by the natural mode of the carbody excited at a certain running speed. This natural mode is the upper swaying mode of the carbody and has an eigenfrequency of about $2.5 \mathrm{~Hz}$. When the wheel-rail equivalent conicity is relatively large in case of wheel wear, the frequency will convert with the hunting frequency of the bogie with the increase of speed, leading to carbody hunting instability.

(4) The equivalent conicity of wheel-rail contact becomes larger after wheel wear, which leads to the abnormal vibration of the carbody and reduces the riding comfort. Therefore, it is recommended to monitor the wheel wear and maintain it in a timely manner to ensure that the operational status is good in actual operation of metro vehicles.

\section{Data Availability}

The data used to support the findings of this study are available from the corresponding author upon request.

\section{Conflicts of Interest}

The authors declare that they have no conflicts of interest.

\section{Acknowledgments}

This research was partially supported by National Natural Science Foundation of China (Grant no. 51975485), Sichuan Science and Technology Project (Grant no. 2020YJ0074), the Fundamental Research Funds for the Central Universities (Grant no. 2682019CX46), and Independent Research and Development Project of the State Key Laboratory of Traction Power (Grants nos. 2019TPL-T18 and 2019TPL-T22). 


\section{References}

[1] Z. David, W. Wang, and H. K. Lo, "Financial sustainability of rail transit service: the effect of urban development pattern," Transport Policy, vol. 48, pp. 23-33, 2016.

[2] C. Zou, Y. Wang, P. Wang, and J. Guo, "Measurement of ground and nearby building vibration and noise induced by trains in a metro depot," Science of the Total Environment, vol. 536, pp. 761-773, 2015.

[3] G. Diana and F. Cheli, "The development of a numerical model for railway vehicles comfort assessment through comparison with experimental measurements," Vehicle System Dynamics, vol. 38, pp. 165-183, 2010.

[4] C. H. Huang and S. L. Liang, "Study on influence factors of low-frequency car body swaying for high-speed vehicles," Electric Drive for Locomotives, vol. 1, pp. 16-20, 2014.

[5] G. Kouroussis, O. Verlinden, and C. Conti, "On the interest of integrating vehicle dynamics for the ground propagation of vibrations: the case of urban railway traffic," Vehicle System Dynamics, vol. 28, no. 12, 2010.

[6] H. Nie, W. M. Yan, and X. W. Gao, "In situ experiment and analysis of adjacent buildings vibration induced by urban subway transit," Journal of Railway Science and Engineering, vol. 1, no. 12, 2008.

[7] C. Huang, J. Zeng, and S. Liang, "Carbody hunting investigation of a high speed passenger car," Journal of Mechanical Science and Technology, vol. 27, no. 8, pp. 2283-2292, 2013.

[8] P.-A. Jönsson, S. Stichel, and I. Persson, "New simulation model for freight wagons with UIC link suspension," Vehicle System Dynamics, vol. 46, no. 1, pp. 695-704, 2008.

[9] Z. Xia, J. Zhou, J. Liang et al., "Online detection and control of car body low-frequency swaying in railway vehicles," Vehicle System Dynamics, vol. 1, 2019.

[10] D. L. Chen, G. Shen, and C. C. Zong, "Analysis of lowfrequency lateral swaying of metro vehicle based on model tracing," Journal of the China Railway Society, vol. 41, no. 10, pp. 47-52, 2019.

[11] GB/T 5599, "Specification for dynamic performance assessment and testing verification of rolling stock," 2019.

[12] UIC 518, "Testing and approval of railway vehicles from the point of view of their dynamic behaviour-safety-track fatiguerunning behaviour," 2007.

[13] S.-Y. Lee and Y.-C. Cheng, "Hunting stability analysis of highspeed railway vehicle trucks on tangent tracks," Journal of Sound and Vibration, vol. 282, no. 3-5, pp. 881-898, 2005.

[14] Y. Yao, G. Wu, Y. Sardahi, and J.-Q. Sun, "Hunting stability analysis of high-speed train bogie under the frame lateral vibration active control," Vehicle System Dynamics, vol. 56, no. 2, pp. 297-318, 2017.

[15] G. Shen and J. Gu, "Study of dynamic performances of low floor tramcar with modified wheel profiles designed via contact-angle-curve (CAC) method," Journal of Tongji University, vol. 31, no. 10, pp. 1206-1211, 2003.

[16] L. Wei, J. Zeng, M. Chi, and J. Wang, "Carbody elastic vibrations of high-speed vehicles caused by bogie hunting instability," Vehicle System Dynamics, vol. 55, no. 9, pp. 1321-1342, 2017.

[17] K. S. Song, S. G. Baek, Y.-S. Choi, and J. C. Koo, "Effect of conicity on lateral dynamic characteristics of railway vehicle through scaled wheelset model development," Journal of Mechanical Science and Technology, vol. 32, no. 11, pp. 5433-5441, 2018.
[18] O. Polach and D. Nicklisch, "Wheel/rail contact geometry parameters in regard to vehicle behaviour and their alteration with wear," Wear, vol. 367, pp. 200-208, 2016.

[19] H. Shi and P. Wu, "Flexible vibration analysis for car body of high-speed EMU," Journal of Mechanical Science and Technology, vol. 30, no. 1, pp. 55-66, 2016.

[20] R. Luo and H. L. Shi, Dynamics of Railway Vehicle Systems and Application, Southwest Jiaotong University Press, Chengdu, China, 2018.

[21] W. M. Zhai, C. B. Cai, and S. Z. Guo, "Coupling model of vertical and lateral vehicle/track interactions," Vehicle System Dynamics, vol. 26, no. 1, pp. 61-79, 1996.

[22] B. Diedrichs, M. Berg, S. Stichel, and S. Krajnović, "Vehicle dynamics of a high-speed passenger car due to aerodynamics inside tunnels," Proceedings of the Institution of Mechanical Engineers, Part F: Journal of Rail and Rapid Transit, vol. 221, no. 4, pp. 527-545, 2007.

[23] S. H. Zeng and X. X. Chen, "Vehicle dynamic characteristics analysis by using root locus," Institute of Electrical and Electronics Engineers, vol. 1, pp. 969-972, 2015. 